\title{
O olhar da memória: conduto do tempo
}

\author{
Lenice Pimentel Cabral ${ }^{1}$
}

O que olhar no texto ficcional? A leitura, produzindo efeitos encantatórios, atualiza a memória que se queria para sempre guardada no baú da vida. O texto literário, vamos perceber, é o espaço de transgredir, de realizar rupturas, de viver desejos, "pois é do veneno da escritura, lugar do tesouro dos significantes, que se constróem os novos mundos da utopia." Tesouro de palavras que, na linguagem, emerge com novos significados seduzindo o leitor. Essa é a demanda da literatura e da psicanálise. Olhar e ouvir para além do "pé da letra" os significantes do texto. O texto da memória ${ }^{3}$ pede complemento. Exige o Outro para que possa se constituir. Exige o olhar e o amor de um terceiro: o leitor.

O texto da memória, aqui ilustrado com "O risio do bordado", de Autran Dourado, faz brandir o lamento de Joào, ser dividido, que ecoa naquele que ouve/ lê pedindo o ato de complementariedade - ato de amor: ponto comum entre a literatura e a psicanálise. Na clínica psicanalítica, o amor de transferência, dando-lhe suporte, tem no saber sua melhor relação. Na literatura, o amor é construído no

'Prof ${ }^{a} \mathrm{Dr}^{\mathrm{a}}$ em Literatura da UFAL e psicanalista do Centro de Estudos Freudianos do Recife. ${ }^{2}$ CASTELLO BR.ANCO, L. \& BRANDÃO, R. S. Literaterras: as bordas do corpo literário. São Paulo: Annablume, 1995, p. 28.

${ }^{3}$ Não estamos tratando do texto memorialístico, mas da memória ficcional.

${ }^{4}$ DOURADO, A. O risco do bordado. $6^{\mathrm{a}}$ ed. São Paulo/Rio de Janeiro: DIFEL, 1976. As citações do livro serão feitas com a sigla $\mathrm{RB}$ seguida do $\mathrm{n}^{\circ}$ da página. O narrador desse romance é o menino Joào que "comparava", "ouvia" e "anotava" o que se passava no seu universo, pois pretendia escrever as histórias de sua familia. Essa pretensão ia além do que tinha vivido, englobava também o que presenciou e o que ouvira contar. Para ele não importava que os fatos ouvidos/vividos/presenciados, tivessem de fato acontecido. Seu desejo era preservar a infância da fome do tempo. Logo, O risco do bordado busca a reconstrução do passado através da memória e da imaginaçào, puxado com os fios de lembranças das "coisas passadas não como realmente tinham acontecido mas acrescentadas, escurecidas, umedecidas de pecados e sombras durante os dias, os meses e anos que passaram mergulhadas nas águas lodosas do tempo, escondidas nos subterrâneos da memória" (RB, 204). A memória, resíduo do vivido, se associa à imaginação para formar a base da ficção e nisso ela é também esquecimento. 
jogo de olhares solicitados para a cena da leitura. Sedutor, o texto enlaça o leitor em sua trama e o texto da memória, voltado para o vivido, encontra no olhar o parceiro ideal para resgatar os fios de imagens fugidias e esgarçantes de um passado já distante e que à revelia do sujeito nào permite a perda total desse vivido. As lacunas da memória, revelando o estado fatal desse conteúdo armazenado, solicitam preenchimento.

No texto de Lúcia C. Branco, A traição de Penélope ${ }^{5}$, a escritora chama a atenção para o perigo de o sujeito ter uma visão petrificada de seu passado e, portanto, "possuir dele uma imagem deformada, paralisada, ou perder para sempre, no gesto de olhar para trás." Pretendendo escrever sobre si e enredado nos fios da memória, Joào, personagem e narrador do texto a ser analisado, nào vê escapatória para o seu desejo. É preciso escrever; voltar o olhar para o passado sem medo de se petrificar para perguntar sobre a origem.

Longe de suturar o vazio que flanqueia os escombros da memória, nossa pretensão é mergulhar no "ventre do tempo" em busca das lembranças gestadas no desassossego de amores edípicos. Essas lembranças, Joào preferia que permanecessem "debaixo de escondidas escamas" (RB, 157), pois receava os efeitos devastadores sobretudo nas noites insones da adolescência quando a figura da màe, no seu roupão vermelho, se confundia com a imagem de Terezinha Virado, em seu roupào de cetim com ramagens.

Nos sonhos,

"as ondas que corriam eram agora lentas, quentes, irreais, desmaiadas [...] Uma alegria medrosa incendiou a alma pequena no seu silêncio de êxtase. [...] E a música em surdina, grave e cheia, solene e grave [...] espalhava a sua alegria impura e pecaminosa na alma desamparada do menino. (RB, 20-21).

Entre a màe e a prostituta, afundado em lembranças, o menino Joào tenta abafar as lembranças quentes do corpo desejado/fantasiado da mãe, envolto no roupão vermelho, respingando água. "O corpo que aos seus olhos de menino era a própria brancura." (RB, 157). Lembranças graves movem o desejo que, em borbotòes, nào se contentam com o sonho e, metonimicamente, recaem sobre a tia Margarida que, "reparando bem era capaz até de ser bonita" (RB, 160); ou sobre Terezinha Virado, na paradisíaca Casa da Ponte, iluminada pelas luzes sedutoras, vermelhas, noturnas, luzes do desejo mais escondido e, paradoxalmente, mais visível.

'C.ASTELLO BRANCO, L. A traição de Penélope. São Paulo: AnnaBlume, 1994.

"Ibidem., p.15. 
Em sonhos, de olhos fechados, em silêncio, no negrume da noite, o perfume da màe, saindo do banho, se misturava ao perfume de leite de rosas de Terezinha Virado envolvendo-o "manso, vagaroso, penetrante" $(\mathrm{RB}, 32)$, inscrevendo "para sempre [o] cheiro de mulher" $(\mathrm{RB}, 34)$ no seu corpo. Porém, é a lembrança da mãe que continua a ser "um ponto dolorido de espanto, um abismo luminoso de dor" (RB, 158) constituindo o "cimento de suas mais fundas lembranças, o chão mesmo do poço" (RB, 158). A matéria imaginada da Casa da Ponte, com suas mulheres, nào suplantava as lembranças infantis, pois inversamente ligava-o ao seu passado.

Seus olhos de menino nào se desprendiam da Casa da Ponte com seus mistérios e a promessa de prazeres indescritiveis. Tudo ali era diferente. Passear os pensamentos por entre os seus labirintos era atividade encantadora que ocupava a imaginaçào do menino Joào. Quando faria seu début nesse mundo de prazeres? Por enquanto, inventava as mulheres a partir dos olhos e da imaginação. "No fundo [...] tinha medo de ir à Casa da Ponte, ver de perto Terezinha Virado" (RB, 25), mas, sobretudo, trair a màe. Ela nào ia entender.

Ela sabendo que ele tinha segurado os pés de Tereqinha V'irado, ao menos tocado num fio de seus cabelos, nunca mais que João podia pôr a mão nela. [...] Se antevia sujo, a pessoa mais suja do mundo.(RB, 27).

É melhor nào pensar. Imerso em fantasias, trancado no quarto, Joào se entrega aos prazeres auto-eróticos. $\mathrm{O}_{\text {gozo }}{ }^{7}$ experimentado, misto de prazer e medo, aponta para a prevalência que Lacan dá ao significante "falo" que, paradoxalmente, em sua materialidade, condensa as satisfaçòes do sujeito, mesmo quando a culpa se faz presente.

Sozinho, João agora tinha pressa de chegar em casa e se trancar no quarto. Cheirou a camisa, cheirou o próprio corpo, cheirou as mãos. Um cheiro de água-de-colonia que fazia lembrar a alfazema da roupa de cama, só que mais grosso, mais oleoso, mais estridente. Um cheiro de Leite de Rosas, que Tereqinha Virado passava nos sovacos raspados, nas pernas lisinhas. Um iheiro de carne quente e umida. [...] Ai, a mãe podia ouvir, podia ver, podia sentir: (RB, 34).

Freud postulou o gozo como uma satisfação pulsional, que engloba prazer e sofrimento colocando a pulsão de vida separada da pulsão de morte. Lacan elimina essa divisão e inova o conceito freudiano sem, no entanto, eliminar o caráter de conflito que envolve a satisfação da pulsão. Aqui, o gozo é apreendido nessa equivalência. 
A pregnância do cheiro nessa passagem permite acompanharmos o movimento desse significante. $O$ cheiro se desprende da memória provocando uma descontinuidade no saber de Joào. Das lembranças inquietas da infância, explodem medo e satisfaçào mesclados num só objeto. Apreensivo, Joào vai substituindo as fantasias em torno da mãe: incapaz de conter a excitaçào e o prazer concentrado no falo, teme ferí-la com suas fantasias e ser desmascarado nos seus desejos. Essas lembranças o fazem recolher-se ao quarto com receio de ser traído pelo cheiro, pelo sumo que tomava todo o seu corpo, seu coraçào. Todo ele exalava desejo. De certa forma, ele sabia que o ato de remexer na memória provocava dor, uma "pasta de dor dentro dele; esta ele esquecia, não queria nem mesmo nas noites insones, afogado em tentação e pecado, lembrar: o corpo que aos seus olhos de menino era a própria brancura" (RB, p.157) provocava sofrimento. Insistentemente, a figura branca da màe se fundia com as lembranças de Teresinha Virado, na Casa da Ponte: "as duas figuras se fundindo num só corpo leitoso e nevoento na escuridão da memória. Em suas noites ele sofria. Meu Deus, como elas eram parecidas! (RB, p.158). Sem que ele pudesse evitar, Terezinha aparecia de roupão vermelho.

Essas citações nos levam a perguntar: o que fica como registro, como marca, no tecido da memória? Parece-nos que algo de importante aí fica registrado: o que é significativo para a história do sujeito aí se inscreve com seus significantes enquanto letra". Na sua descontinuidade a memória vai girando os vários traços" que aí se inscreveram. É, pois, a partir desses conceitos que entendemos a tentativa de Joào desejar, incessantemente, apagar o traço para que possa sair do labirinto de Dédalus. Com base nessa articulaçào, Lúcia Castello Branco vai dizer que o insano ofício do sujeito em luta com suas memórias é o de "tecer, com a urdidura do esquecimento, a trama da lembrança: traçar, com os riscos de uma escrita apagada pelo tempo, as letras de uma nova escrita"l" capaz de transportá-lo para outro lugar. Esse é, talvez, o trabalho contínuo das terras da memória; terras de lituras ${ }^{11}$ - incansável no

\footnotetext{
"Lacan designou o termo Letra como sendo o que aparece após a leitura: a "escrição". A Letra se encontra ao lado do Real, fazendo "rasura de todo traço que esteja antes".

"O traço é o que marca o corte, a ruptura e ao mesmo tempo, liga, transporta, dando a ilusão de um tempo contínuo aos fatos vividos. O traço é um fragmento do sujeito.

"CASTEllo BR.ANCO, L. A traigão de Penélope. p. 41.

"Vem de Lacan a idéia de rasura. A rasura é uma sucessão de traços que se recobrem, na tentativa de se apropriar da palavra verdadeira. Aproximar palavra e coisa. Nesse sentido, a "rasura é de nenhum traço que seja anterior". Indicamos a leitura do artigo de Lacan - Ormicar? Revue du champ freudien, n. 41.
} 
movimento de aterrar e cavar o lixo ${ }^{12}$ das lembranças. Freud, ao tratar do traço mnêmico, indica o caminho para vários teóricos que se dedicam à questào do tempo e da memória. Esse conceito, também ele descontínuo, é um elo de ligaçào temporal entre os fatos vividos e ou nào. Na ilusào de um tempo contínuo, o traço possibilita a passagem porém "ele nào tem como deixar de marcar o abismo temporal, o vazio, a lacuna - e para isso contribui seu caráter de signo peculiar, de signo que significa sem fazer aparecer:" ${ }^{\prime 3}$ Nesse sentido, nos deparamos com a descontinuidade temporal e com a rasura da origem.

\section{Porāo da memória: lugar do desejo}

Assustado, Joào fala/escreve suas memórias para encenar sua própria falta; seu próprio desejo. Iça do porào da memória o que, insistentemente, se encontra sob as escamas do vivido, sabendo ser impossível a sua captura. $O$ tempo, descontínuo, se interpòe no caminho de recomposiçào da memória. O poço de Mnemosyne, deusa da memória, é turvo e inquieto e dessas águas turbulentas algo se agita nas lembranças de Joào: a visão da "mulber nua que saia do banho ainda molhada e recendendo [...] Esse era o seu pecado mais fundo, a sua maior dor; embora ele nada tivesse feito, nenhuma culpa lhe coubesse" (RB, 158). Na teoria dos mitos vamos encontrar, através da deusa Mnemosyne, memória e esquecimento aliados no mesmo ato. Essa concepçào implica a impossibilidade de conservar o passado intacto. No presente, as lembranças surgem com as rasuras, as manchas do tempo. Entrelaçar a imagem da màe, de Terezinha Virado e da Tia Margarida é o que podemos entender como deslocamentos metonímicos para o preenchimento das lacunas da memória de Joào. Édipo errante, a angústia que se traduz pelo pecado nào cometido é mais vívida porque construida a partir do que ainda nào é, mas pode vir a ser. Triunfante, Mnemosyne canta "tudo o que foi, tudo o que é e tudo o que será" e futuro se alinham nessa construçào que se apóia na memória. Memória do

\footnotetext{
12 Lixo, aqui, tem a noçào que Lacan desenvolve no "O seminário sobre 'A carta roubada"' (1956), associado à expressão "a letter, a litter", onde observamos a dupla dimensão de uma carta/letra: funçào de transmitir uma mensagem, a letter, e o destino que concerne sua materialidade, alitter.

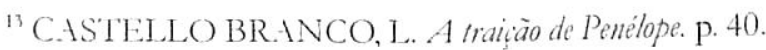

${ }^{4}$ HESÍODO citado por VERN.ANT. Mito e pensamento entre os gregos, p. 73.
} 
passado; memória do futuro ${ }^{15}$. Nas palavras freudianas, o desejo sexual inconsciente, base do Édipo, fica impregnado com o cheiro, o toque, a voz e o olhar da màe. Para o menino, frente à mãe, não há outro caminho senão o de fazer dela seu privilegiado objeto de amor. O difícil, para ele, é sair da fatal simbiose salvaguardando sua integridade: e escrever sua história é o caminho para rever a integridade pois ao se debruçar sobre o peitoril de seu passado, inevitavelmente, é o futuro que seu olhar espreita.

Nesse movimento, o menino Joào, frente às mulheres, sabe de um saber de amor que já está lá; que pode ser revivido porque já experimentado. Esse saber, bordado com a memória, reaparece nas situaçòes de seu cotidiano: nas marcas do cheiro, do roupão vermelho, do roupão de ramagens, da visão da mulher produzida pela imaginação infantil fomentada pela imagem da mãe saindo do banho. Grávido dessas recordações é capaz de "miraginar" suas lembranças de futuro. Tecido esgarçado, a memória nào cessa de solicitar complemento. $O$ trabalho para construir a matéria de preenchimento para as lacunas da memória é atividade incansável para o sujeito. Bachelard, ${ }^{16}$ apoiado no conceito de durée, de Bergson, entende que essa construção de sujeito é dolorosa, sobretudo "diante da angústia que significa para ele a experiência da memória, o ato de reviver o desaparecido"17. O ato de reviver o desaparecido implica adentrar no processo de descontinuidade que marca a memória e, ao mesmo tempo, o aproxima da angústia da morte: é por isso que o texto solicita cautela para adentrarmos no seu sentido. Amando, gostando, estabelecemos com ele uma relaçào de intimidade até chegar o momento de analisálo a partir dos jogos de significantes suportado pelo olhar desejante. Olhando para o passado o menino Joào reencontra a tia Margarida em sua relaçào erótica com a leitura:

... de olhos graúdos de jabuticaba-do-mato, as pestanas grandes $e$ pensativas; o nariz fino, iaprichosamente torneado, bem acepilhadinho, feito como sob o risco de régua e compasso, as asas que se abriam ou fechavam como pétalas em sonho, no ritmo vagaroso da respiração calma, ou mais rápidas, conforme a parte do livro que estava lendo, ou, ela sem ler; a aparifiào com certeza de um pensamento mais buliçoso; a boca farta, os

15. Autran Dourado entende que a memória não é fixada no passado. A memória é também memória do futuro. Na perspectiva do mito de Mnemosyne, garantindo a função poética da linguagem, cabe ao poeta o Dom da vidência, unindo memória e futuro.

${ }^{16}$ B.ACHEL ARD. G. A dialética da duração. São Paulo: Ática, 1988.

'C. ISTELLO BR.ANCO, L. A Iraição de Penélope, p. 28. 
lábios corados e carnudos que ela ia umedecendo de vę em quando com a pontinha da lingua. $(\mathrm{RB}, 160)$

Essa passagem revela o que tia Margarida dissimula na vida: ser uma solteirona conformada. No ato da leitura algo escapa desse contorno riscado à régua $\mathrm{e}$ compasso, abolindo os limites. Entre o livro e o olhar da tia Margarida encontramos o que a psicanálise define como gozo. ${ }^{18}$ Transgredindo o território do Pai, os olhos pairam nos campos do gozo; gozo feminino - nào-todo, explosivo e contido na órbita dos olhos que brilhavam quase silenciosos no seu espocar de gozo. Distante, com os pensamentos em efervescência, o gozo faz limite com a morte, a loucura, o Real, o indizível e impossível de ser capturado em outra linguagem que nào a do corpo. A respiração sôfrega, a boca que se entreabre em lentos movimentos, irrompe para outras terras que nào se ressentem do silêncio. O corpo assume a cena mostrando o texto que aí se inscreve com os riscos do desejo, mesmo que erradio fazendo do texto o grito quase silenciado da tia Margarida. Voláteis como o desejo, os pensamentos fazem algazarra no ar descortinando a cena da leitura num desejo ardente que dói mostrando que o tempo do eu-Margarida nào coincide com o tempo do mundo-Margarida, captado pelo fulgor adolescente de Joào como metonímia e metáfora da mulher desejante ao se revelar em seu teor erótico através do ato da leitura, uma vez que visa, precisamente, se deslocar para representar tudo aquilo que lhe falta: ser capturada pelo olhar do pai; para um mais-além. Os olhos, condutores metonímicos do desejo, não encontram desaguadouro e se petrificam no desejo de um Outro. Se "os olhos são apenas conduto" para o desejo e o olhar é o que importa porque pulsa no ritmo do corpo que deseja, tia Margarida mostra que o tempo do vivido nào se cruza com o tempo rememorado mesmo quando os sonhos do presente sào tecidos com os fios do passado que tecem a rede significante do seu próprio bordado com finas tessituras. Nos buracos intervalares da leitura ela captura o universo dos significantes em sua algazarra e arranca o recalcado que se aloja nas linhas do texto para atualizar e gozar os desejos em seus mistérios. Nesse tecer os fios do bordado, a ficçào se afirma como esse "espaço-entre" que moldura e estrutura os fantasmas. Aqui, as palavras de Ruth Silviano fazem eco com o meu pensamento ao ver na ficçào o lugar "onde o fingido é o real que irrompe e alucina,

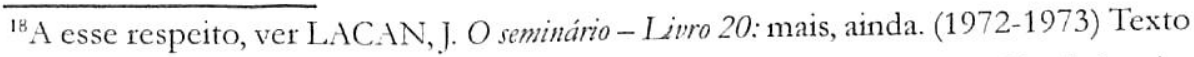
estabelecido por Jacques-.Alain Miller. Versão brasileira de M. D. Magno. Rio de Janeiro: Jorge Zahar, 1985.

"Essa expressão se encontra no livro "Ópera dos mortos", de Autran Dourado, p. 2
} 
onde a razào perde a razào e a lei é a do verossímil, nào a da verdade, esse incapturável impossivel." ${ }^{20}$ Voltando a tia Margarida, nela o tempo passava lentamente, quase imperceptivel dando a ilusào de continuidade "porque as mudanças de tia Margarida devem ter se passado tào lentamente como muda uma montanha, aos nossos olhos eternamente parada e cujas mudanças só são percebidas pelos olhos de Deus" (RB, 185). Deslizante, enigmática e lacunar, tia Margarida permanece não-toda para os olhos de Joào, para o desejo do Outro cujo olhar contorna o furo, o enigma, o vazio. Algo escapa; sempre escapa.

Bons tempos aqueles em que nas férias do colégio, passadas na casa dos avós, tia Margarida era matéria para os sonhos do João adolescente que surgia como um "touro de chifres vermelhos, saltando, mugindo no labirinto escuro, sanguinolento" (RB, 179) tentando desesperadamente "afogar na memória, enterrar na paradeza do tempo" (RB, 178) as lembranças lodosas da infância. Diferentemente da velhice (morte) que tentava aparentar, Tia Margarida podia ser bonita "se caprichasse no trato, se soltasse aquele cabelo". (RB, 160). Do porão da memória surge tia Margarida emoldurada por um halo de luz. Diáfana, branca, esticada na janela, se oferecia para seus olhos em sua

camisola de rendas [...] Toda branca, ela parecia mais branca do que realmente era. Os cabelos compridos, soltos e pretos, lustrosos, brilhavam, caindo em ondas sobre os ombros. [...] Linda, ele achava-a linda (RB, 181).

Fascinado, Joào nào podia desviar os olhos da figura "diáfana e branca" que emergia do escuro da noite. Seduzido pela visào, fixava-se na nudez branca que explodia em luz. "Toda ela nudez e luz: diáfana, pura, leitosa. [...] a nudez que via era maior do que toda nudez que sonhara" (RB, 182). Rasgando o ventre da noite, exalava o cheiro de dama-da-noite. Diante do que via, o minotauro mugia no peito adolescente de Joào conjugando dor e afliçào no prazer de ver. João, confuso, "fechou os olhos, com medo de ver" (RB, 181). Temia que essa imagem confluísse para uma outra, mais antiga, e por isso tinha medo de abrir os olhos. Mesmo de olhos fechados

dentro dele espocavam gritos, foguetes na escuridão. Eram palauras gritadas por boias vermelhas, de dentro de negros labirintos. Nudez, mistério, braniura, morte! Exxtase, transe, fascinio, agonia, ressurreiçãa! Todo ele eletriqudo, à espera de morrer (RB, 182).

211 BR.IND.̇O, R. S. Literatura e psicanálise, p. 45. 
A relaçào entre Eros e Thanatos, abordada por Freud, revela-se na impossibilidade de expressar a sexualidade. Como a morte, a sexualidade é obscena. Silenciosa e se deixando apreender pela visão, Margarida realiza a transgressào possível nos seus domínios. Na casa do pai, o papel de solteirona lhe caía como uma luva nessa aproximaçào com Thanatos.

Mais tarde, nas férias seguintes, Joào observa os efeitos do tempo em Tia Margarida que parecia ter conseguido empurrar para os campos de Mnemosyne todo desejo; tudo o que se passara entre eles. De roupas escuras, cabelos presos, silenciosa, tudo fazia para apagar as lembranças. Impossível. Mnemosyne, astuciosa, mostrava sua força e "uma ou outra vez [captava os momentos em que] ela falseava a voz" (RB, 186) ou deixava escapar um olhar, um soluço, a gagueira, um remexer de coxas, um arfar da respiraçào quando um pensamento buliçoso se intrometia no seu caminho.

Para Joào, já deixando para trás o menino, as imagens da mãe, de Terezinha Virado e da tia Margarida continuavam entrelaçadas em sua memória. Quando as lembranças de menino rasgavam o véu do tempo e teimavam em povoar seus pensamentos era para Terezinha Virado, com suas escondidas promessas, que ele se voltava e "tudo [...] lhe restituía os dias antigos, as coisas passadas nào como realmente tinham acontecido mas acrescentadas, escurecidas, umedecidas, contaminadas por outras lembranças [...] escondidas nos subterrâneos da memória” (RB, 174). O que se pode apreender dessa passagem é que a memória é construida do mesmo tecido do qual se retiram os fios para tecer o esquecimento. No risco do bordado, os fios sào tingidos com as cores do já vivido e com o desejo do devir.

Metaforicamente, esse entrelaçamento é um jogo de espelhos que (re)apresenta uma nova mulher conforme o momento de Joào. Os fragmentos das lembranças da màe remetem para as outras lembranças movendo o desejo em novas dimensòes e fazendo do sujeito o lastro para que o ato da memória se efetue em movimentos constantes.

Na angústia que a lembrança do corpo nu da màe provocava, outras invençòes de mulher se faziam necessárias:

Quando ingressava na zona sombria e pastosa em que é dificil saber se já estamos ou não dormindo, se sonhamos ou apenas lembramos, surgia das sombras aquele vulto branio, aquela nudeq fluorescente, aquele corpo feito de quentume e cheiros grossos es estridentes, que ele procurava tapar com o roupão vermelho, e gritava do fundo da lama escorregadia, das areias movedicas em que se afundava, Tereqinha Virado, ai Terezinha T irado. para ressuscitar (o grito estrangulado na garganta), acordar do pesadelo $\mathrm{c}$ 'n 
que ia se afundando. Porque não era com Teresinha Virado que ele ia sonhando, Teresinha Virado era a bóia de salvação. (RB, 174).

Na mulher da Casa da Ponte ele podia se agarrar para se livrar dos desejos interditos, da angústia e dos pecados. Na dor de Joào são o silêncio e a angústia que sobressaem por entre os funebrilhos das lembranças que estimulam o preenchimento dos espaços em branco que nascem da insistência para procurar motivos. No percurso das lembranças primeiras é preciso fazer desvios, tropos para escavar o sítio arqueológico da memória e nele descobrir as rupturas, a fragmentaçào, a descontinuidade, os vazios a serem preenchidos. Na tessitura da linguagem/escrita, Joào encena sua falta produzindo sentidos, produzindo ficçòes e, por isso mesmo, produzindo a memória do futuro. Angustiado, busca na palavra refazer os vazios de sua existência: entre o antes e o depois, em duplo movimento, a memória vai sendo construída. A psicanálise desenvolve bem essa concepção sobretudo no artigo "Uma nota sobre o bloco mágico"21 e "Construçōes em análise"22: no primeiro texto, Freud observa que o papel que recebe uma escrita, com o tempo, deixa que algo se perca restando-lhe traços, inscrições possiveis de uma recuperação futura. Processo semelhante se dá com o sujeito que pretende recuperar sua história; este se fará em cima das falhas, faltas, rasuras, vazios mostrando que é no campo do simbólico que literatura e psicanálise se encontram. Essa aproximação fica mais evidente no segundo texto, quando Freud coloca a memória no centro do processo analítico implicando, sempre, a memória e o esquecimento. Mnemosyne (memória) e Lethe (esquecimento) se olham e se complementam.

Como assinala Deleuze ${ }^{23}$, o tempo da memória pode ser o próprio tempo da escrita. Tempo que se inscreve entre o labor do escrito e a reconstruçào da imagem perdida no qual o tempo da escrita já não é o tempo do vivido e, dessa forma, o acesso é ao passado representado. O presente é fugidio como podemos observar no seguinte fragmento:

E cada dia, cada mês, uma nova marca (um pêlo, uma espinha, um fio de barba) ia assinalando a mudanca que dentro dele se processava velo zmente [...] O nariz grosso, o queixo pesado, o inchume dos lábios, o buço, mesmo

\footnotetext{
${ }^{21}$ FREUD, S. "Notas sobre o bloco mágico" - (1925). Vol. XIX.

${ }^{22}$ FREUD, S. "Construções em análise" - (1937). Vol. XXIII.

${ }^{23}$ Deleuze entende que o tempo perdido, o tempo proustiano, não se compõe só do passado, mas do tempo presente no discurso, na escrita. Ver: DELEUZE., G. Diferença e repetição. Rio de Ianeiro: Graal, 1988.
} 
os olhos agora ganhando um brilho duro e agressivo, de aço, iam alterando, apagando, esfumando os uiltimos vestigios do menino bonito que ele tinha sido. E a vo que a ele mesmo espantava, de tão grossa, cujo timbre ele não conseguia controlar, que ainda não tinha ganbo o seu próprio corpo e volume, e às veques era motivo de chacota dos mais velhos.

Assim, podemos dizer, o tempo é o Real escorregadio, sempre sendo; sempre passado re-presentado.

\section{A bordadura do risco}

No Risco do bordado, reencontramos ressonâncias de muitas outras histórias. Os fios da trama tentam seguir o risco pré-estabelecido para a história a ser narrada. João, voltando seu olhar para o passado, conta/escreve sua história; como tia Margarida, que esquece o que está lendo para ir a outros mundos, ele pensa traçar novos riscos para o seu bordado, mas, edipicamente, (re)encontra o primeiro risco: o risco da màe. É desse saber que o ser humano anda à procura. João escreve, risca seu risco; move seu desejo encenando a própria história. A psicanálise, a esse respeito, entende que há um ponto em que é impossivel re-encontrar com o risco primeiro: o umbigo do risco, que insiste em deslizar em novos riscos, em novos sentidos. Ruth S. Brandào em Literatura e psicanálise, sublinha a interseçào dessas áreas mostrando que:

Nesse sentido amplo, a Psicanálise trabalha com o texto escrito, reescrito, iopiado, invertido, produzido por variadas vozes e que constitui a verdade de cada sujeito falante que deixa fluir esse discurso. Discurso que flutua entre ele e alguém que escuta. Alguém - opsicanalista - que tem uma escuta especialissima e vai pontuando, sublinhando, re-escrevendo, por sua veq esse texto flutuante. Original, cópia, traduläo? Reescritura? Fição? Reconstruica - produto/produção, processo arqueológico, restauração. ${ }^{2+}$

Com a psicanálise, a literatura começa a se re-pensar como letra ${ }^{25}$ debruçandose "em seus jogos de sentido, sabendo que no próprio trajeto de seus ruídos se faz

\footnotetext{
${ }^{24}$ BRANDÃO, R. Silviano Literatura epsicanálise. Porto Alegre: Ed. Universidade/UFRGS.1996, p. 38. ${ }^{25}$ Letra, conceito lacaniano, desenvolvido no Seminário18 - D'un discours Qui ne serait pas du semblant - (1970-71) se encontra do lado do Real: entre "escrição", escrita e leitura. A Letrá é a "terra do litoral" que faz "rasura de todo traço que esteja antes".
} 
ler, se soletra e aí se apaga o sujeito, ai ele se apresenta como significante" ${ }^{26}$ com sua inscriçào singular. Escrever é sua forma de ir em busca do invisível, do impossível, mergulhando na "dimensào temporal descontínua da memória"27 para fazer limite entre a memória e a ficção, uma vez que "a literatura é o fulgor do Real", como assinala Barthes. A linguagem aí é encenada para criar a fantasia e o sonho; para ensinar a olhar, a amar. Para ensinar a mirar o texto e imaginar o que tem dentro do baú feito de memórias. Invisivel, a memória permite "miraginar" o que foi escrito em seus pergaminhos. Mirar c olhar com amor sào as armas para a construçào de um novo texto; uma nova criaçào; um novo conto. Trazer algo novo para colocar no lugar do morto. Nesse sentido, estaríamos realizando o duplo movimento exigido pela memória: esquecer e rememorar como nos ensina Freud em seu texto sobre o ‘bloco mágico' é recuperar o traço, presumir a perda, a desmemória, o esquecimento, o vazio. Um vazio estruturante para o sujeito. É esse toque especial da literatura que fascina a psicanálise e que tanto ajudou Freud a desenvolver sua teoria. Os textos literários, as personagens, a estrutura da obra, a criaçào, tudo isso interessa à psicanálise pelo seu poder de criar o "efeito do real", pois "a verdade, seja lá qual for, só é acessível pela mentira, pela trapaça, pela invençào e pela imaginaçào da arte...”2\&, ou pelo discurso do analisante que encontra uma brecha no seu próprio texto para (re)escrever sua história, permeada de tantas outras histórias. Esse processo faz parte do mergulho no mar de memórias, via linguagem.

Mergulhando nas águas de Mnemosyne, vamos percebendo que o nosso operador conceitual - a memória, no recorte teórico que vem da psicanálise - é o que leva o menino Joào a descobrir seu universo; a percorrer o caminho daquilo que foi suprimido e censurado por ser vivido como pecado, como traição à mãe. À semelhança da repressào - operaçào psíquica que retira da consciência os conteúdos desagradáveis - os significantes suprimidos tendem a reaparecer frente aos es tímulos do cotidiano. No campo da memória algo falta, mesmo quando está lá não é acessível. A falta é o que pòe em açào o funcionamento metonímico e, ao mesmo tempo, aparece como metáfora por estar sempre apontando para o retorno do reprimido. O que o menino Joào vê no corpo da màe é o seu desejo uma vez que o sentido do significante está em relaçào ao sujeito.

\footnotetext{
${ }^{26}$ BRAND.̃O, R. S. Literatura e psicanálise p. 59.

${ }^{27}$ CASTELLO BRANCO, A traição de Penélope. p. 18.

${ }^{26}$ C.IIVINO, Ítalo. Para ler os clássicos. Sem outros dados.
} 
A repetiçào evocada pela memória, em psicanálise, é apenas um lugar. $O$ que se repete é o que ficou marcado com o signo do perdido para sempre, do "objeto a" da psicanálise lacaniana, o que nos permite englobar no funcionamento do princípio do prazer a compulsào à repetição sustentando a marca que implica o sujeito, o menino Joào, nas suas fantasias e no seu pecado e a tia Margarida, que dói de desejo, ruma para o gozo místico da Verônica e diante do pai ela se apresentava.

O vestido comprido como uma mortalha, roxo da cabega aos pés. A cabeça baixa, os olhos postos no ihão. Os pés descalços, sujos e feridos, em que ela prendera duas grossas correntes que ia arrastando penosamente (RB,188).

Nessa aparição, tia Margarida re-afirma sua condição de não-toda e sob o olhar do pai e de Joào, já rapaz, continua metáfora de um desejo deslizante que se esgueira por entre o "rabo da procissào", sem destino, sem paradeiro. Assume ares de loucura, de absurdo, de gozo. Assume seu risco. 


\section{Referências bibliográficas}

BACHELARD. G. A dialética da duração. São Paulo: Ática, 1988.

BOSI, Ecléa. Memória e sociedade: lembranças de velhos. $2^{\mathrm{a}}$ ed. São Paulo: T. A. Queiroz, 1983.

BRANDÃO, R. Silviano. Literatura e psicanálise: riscos de uma leitura psicanalitica.

Porto Alegre: Ed. Universidade/UFRGS.1996.

CASTEllo BRANCO, L. A traição de Penélope. São Paulo: AnnaBlume, 1994.

CASTELLO BRANCO, L. \& BRANDÃO, R. S. Literaterras: as bordas do corpo literário. São Paulo: Annablume, 1995.

DELEUZE., G. Diferença e repetição. Trad. Luiz Orlandi e Roberto Machado. Rio de Janeiro: Graal, 1988.

DOURADO, A. O risco do bordado. $6^{\mathrm{a}}$ ed. São Paulo/Rio de Janeiro: DIFEL, 1976.

FREUD, S. "Uma nota sobre o 'bloco mágico"” - (1925). Rio de Janeiro: Imago, 1976. p.283-290: Edição Standard Brasileira das Obras psicológicas completas de S. Freud. Vol. XIX.

FREUD, S. "Construções em análise" - (1937). Rio de Janeiro: Imago, 1975. p. 289-304: Edição Standard Brasileira das Obras psicológicas completas de S. Freud. Vol. XXIII.

LACAN, J. Ornicar? Revue du champ freudien. Paris: n. 41.

LACAN, J. O seminário - Livro 20: mais, ainda. (1972-1973) Texto estabelecido por Jacques-Alain Miller. Versào brasileira de M. D. Magno. Rio de Janeiro: Jorge Zahar, 1985.

LACAN, J. O Seminário. Livro 18: D’un discours Qui ne serait pas du semblant. (1970-71) Paris.

LACAN, J. Escritos. Trad. Inês Oseki-Depré. São Paulo: Perspectiva, 1978. 